\title{
O MÉTODO DO POTENCIAL ESPONTÂNEO (SP) - UMA REVISÃO SOBRE SUAS CAUSAS, SEU USO HISTÓRICO E SUAS APLICAÇ̃̃ES ATUAIS
}

\author{
José Domingos Faraco Gallas ${ }^{1,2}$ \\ Recebido em 23 fevereiro, 2005 / Aceito em 29 agosto, 2005 \\ Received on February 23, 2005 / Accepted on August 29, 2005
}

\begin{abstract}
This paper synthesizes the results of a compilation and integration of the most important papers and textbooks dealing with the self potential method (SP), also taking into account the author experience on the subject. Furthermore, it introduces survey and processing techniques as well as presentation and interpretation modes.

A short description of the SP generation processes, related to both mineral exploration and ground water flow studies, is presented. In the former case, the usually negatives SP anomalies are ascribed to the presence of massive sulphide bodies (electrical conductors). In the case of environmental or engineering studies, the main application of the SP method is to determine the sense of the ground water flow.

The occurrence of noises, and the way of eliminating or minimizing them, are considered. The distinct applications of the SP method as well as the expected results from different situations and possible interpretations are also discussed.
\end{abstract}

Keywords: self potential, SP, applied geophysics.

RESUMO. Este trabalho tem como objetivo realizar uma compilação, integração e síntese das principais bibliografias que tratam do método do potencial espontâneo (SP), bem como a experiência do autor em diversos trabalhos envolvendo a aplicação do método. Também trata das técnicas de aquisição, processamento, apresentação e interpretação dos dados.

Descreve-se de maneira sintética os processos de geração do SP nos casos de prospecção mineral e de movimentos das águas subterrâneas. No primeiro caso, as anomalias SP, geralmente negativas, são relacionadas à presença de corpos de sulfetos maciços que comportam-se como condutores elétricos. Em casos ambientais ou de engenharia, tem sua principal aplicação no estudo dos movimentos da água em subsuperfície.

Também são descritos os ruídos presentes e as formas de minimização dos mesmos, bem como correções de dados e apresentação de resultados. São abordadas as diversas possibilidades de aplicação do método, bem como os tipos de resultados esperados em diferentes situações e as interpretações cabíveis.

Palavras-chave: potencial espontâneo, SP, geofísica aplicada.

\footnotetext{
1 Universidade do Vale do Rio dos Sinos - Unisinos, Av. Unisinos, 950, 93022-000 São Leopoldo, RS. Fone: (51) 5903333 R-1766; Fax: (51) 590 8177 -E-mail: jgallas@euler.unisinos.com.br

2Universidade de São Paulo - USP, Rua do Lago, 562, 05508-080 São Paulo, SP. Fone: (11) 3091 4232; Fax: (11) 30914207 - E-mail: jgallas@usp.br
} 


\section{INTRODUÇÃo}

Este trabalho tem como objetivo realizar uma compilação, integração e síntese das principais bibliografias que tratam do método do potencial espontâneo (SP). Também toma como base a experiência do autor em diversos trabalhos envolvendo a aplicação do método, tratando das técnicas de aquisição, processamento, apresentação e interpretação dos dados.

Os primórdios da aplicação do método SP foram na prospecção mineral, sendo aplicado posteriormente em geotermia, perfilagens de poços e atualmente tem sido usado em aplicações ambientais, em geologia de engenharia e hidrogeologia.

A primeira notícia de utilização do método SP é de 1830 quando Robert Fox (apud Telford et al., 1990) usou eletrodos de cobre e um galvanômetro objetivando delimitar e extensão de uma jazida de cobre em subsuperfície. Desde 1920 o método tem sido empregado de maneira rotineira como método complementar na prospecção de metais-base.

É um método de campo natural e baseia-se no fato de que na ausência de um campo elétrico criado artificialmente, é possível medir uma diferença de potencial entre dois eletrodos introduzidos no terreno. Em alguns casos, na presença de bons condutores (sulfetos maciços, preenchimento de fraturas com argilas saturadas, tubulações metálicas), esta tensão pode atingir algumas centenas de milivolts.

A principal vantagem é sua simplicidade, tanto instrumental como operação de campo, além dos baixos custos envolvidos. Para um levantamento SP necessitam-se basicamente dois eletrodos, um milivoltímetro e fios devidamente isolados para as conexões entre os eletrodos e o milivoltímetro.

0 potencial natural ou espontâneo (SP) é causado por atividade eletroquímica ou mecânica. A água subterrânea é 0 agente mais importante no mecanismo de geração de SP. Os potenciais podem estar associados à presença de corpos metálicos, contatos entre rochas de diferentes propriedades elétricas (principalmente condutividade), atividade bioelétrica de materiais orgânicos, corrosão, gradientes térmicos e de pressão nos fluidos de subsuperfície.

Em se tratando de prospecção mineral as anomalias SP, geralmente negativas, são relacionadas à presença de corpos de sulfetos maciços que comportam-se como condutores. 0 fenômeno, neste caso, é explicado por reações eletroquímicas na interface corpo/rocha encaixante nos níveis acima e abaixo do nível freático. A origem do conjunto destas reações é baseada nas diferenças de potencial "redox" nestes dois níveis separados pelo N.A.

0 método do potencial espontâneo em casos ambientais ou de engenharia, tem sua principal aplicação no estudo dos movimentos da água em subsuperfície. As anomalias de SP são geradas pelo fluxo de fluidos, de calor ou de íons no subsolo, e seu estudo tem sido útil para localizar e delinear estes fluxos e as fontes associadas.

\section{O SP NA PROSPECÇÃO MINERAL}

A origem do fenômeno do potencial espontâneo em mineralizações é de natureza eletroquímica. No entanto, existem dúvidas e controvérsias sobre as reações e de que modo estas ocorrem.

A teoria mais aceita para explicar as causas das anomalias SP associadas a mineralizações sulfetadas foi proposta por Sato \& Mooney (1960). Através do estudo de inúmeros casos históricos constantes na bibliografia, estes autores chegaram às seguintes constatações:

a) Os corpos mineralizados associados a anomalias SP são bons condutores eletrônicos, com continuidade elétrica em seu interior.

b) $0 \mathrm{SP}$ é quase sempre negativo nas partes superiores do corpo.

c) A diferença de potencial total pode ser de centenas de milivolts. Há casos onde a anomalia ultrapassa 1,3V e um registro de 1,8V (Gay, 1967).

d) A mineralização deve posicionar-se em parte na zona de oxidação.

e) 0 potencial espontâneo é razoavelmente estável no tempo.

Baseando-se nestes fatos e nas argumentações anteriores, Sato \& Mooney (op. cit.) concluem que as anomalias SP são ocasionadas por dois tipos de reações eletroquímicas. Estas reações localizam-se em duas diferentes posições da interface mineralização/rocha encaixante, sendo uma acima e outra abaixo do lençol freático, funcionando o corpo sulfetado como uma ligação elétrica entre estas posições/reações. As substâncias dissolvidas na região próxima à parte superior do corpo sofrem redução, tomando elétrons provenientes do corpo mineralizado. Por outro lado, as substâncias em solução situadas nas porç̃oes inferiores do corpo sulfetado se oxidam, cedendo elétrons a este, que funciona como uma ponte para os elétrons. 0 fluxo de elétrons de baixo para cima faz com que as reações 
possam manter-se indefinidamente, não intervindo nas mesmas, mantendo-se a mineralização praticamente.

Assim, a origem destas reações é explicada pela diferença do potencial de oxidação Eh (ou potencial redox) que ocorrem nas partes superior e inferior do corpo de sulfetos, produzindo as anomalias SP

Nas proximidades da parte superior do corpo sulfetado, as reações prováveis que ocorrem envolvem o oxigênio livre e 0 íon férrico, tais como:

$$
\begin{gathered}
\mathrm{O}_{2}+4 \mathrm{H}^{+}+4 e^{-} \Leftrightarrow 2 \mathrm{H}_{2} \mathrm{O} \\
\mathrm{Fe}^{+++}+e^{-} \Leftrightarrow \mathrm{F} e^{++}
\end{gathered}
$$

Nas porções inferiores da mineralização, as reações de oxidação mais prováveis seriam as que envolvem o íon ferroso e o hidróxido ferroso, como:

$$
\begin{gathered}
\mathrm{Fe}^{++} 3 \mathrm{H}_{2} \mathrm{O} \Leftrightarrow \mathrm{Fe}(\mathrm{OH})_{3}+3 \mathrm{H}^{+}+e^{-} \\
\mathrm{Fe}(\mathrm{OH})_{2}+\mathrm{H}_{2} \mathrm{O} \Leftrightarrow \mathrm{Fe}(\mathrm{OH})_{3}+H^{+}+e^{-}
\end{gathered}
$$

Concluindo, os elétrons necessários para as reações que ocorrem na zona superior das mineralizações sulfetadas e que têm continuidade elétrica, são oriundos das reações que acontecem na parte inferior do corpo condutor. A energia necessária para manutenção do processo provém do oxigênio atmosférico dissolvido nas águas das chuvas e que penetra no subsolo.

A título de quantificar o fenômeno, Sato \& Mooney (1960) realizaram diversas medidas de Eh e pH no interior e proximidades de mineralizações de sulfetos em zonas mineiras de Utah e Arizona. Concluíram que, na maioria das vezes, as condições encontradas na natureza são tais que as mineralizações se encontram em seu "domínio de estabilidade", não participando das reações químicas que ocorrem, servindo apenas como condutores eletrônicos.

A teoria destes autores implica que o fenômeno SP também pode ocorrer sob condições que anteriormente se julgavam inadequadas. Uma delas é que não é necessário que o corpo sulfetado forme uma faixa contínua de mineralização, posicionando-se parcialmente acima e abaixo do nível d’água. Estas são condições ideais, mas não imprescindíveis. Uma disseminação de sulfetos pode produzir anomalias SP, desde que a separação entre os grãos minerais seja pequena de modo que a condução elétrica entre grãos possa proceder-se ionicamente.

Uma condição necessária é que a rocha hospedeira da mineralização esteja ao menos um pouco alterada, de modo a permitir o movimento de íons.

Casos de rochas compactas e sãs, regiões congeladas ("permafrost" etc) ou zonas desérticas (escassa umidade) não são fa- voráveis para ocorrências de anomalias SP sobre mineralizações. Assim, as condições ideais para a verificação do fenômeno são as de zonas temperadas.

\section{O SP EM HIDROGEOLOGIA, GEOLOGIA DE ENGENHARIA E GEOLOGIA AMBIENTAL}

Em se tratando de prospecção mineral, a teoria de Sato \& Mooney (1960) é a mais bem aceita, apesar de algumas controvérsias. No entanto, quando se trata da aplicação do método para outros fins, tais como hidrogeologia, geologia de engenharia e geologia ambiental, as origens e explicações para o fenômeno são outras, descritas a seguir.

\section{Potenciais de Difusão}

Diferentes eletrólitos em contato ou diferentes concentrações de um mesmo eletrólito nos poros do substrato fazem com que surjam os potenciais de difusão.

Os íons de diferentes polaridades possuem mobilidades distintas e os mais móveis se difundem com maior rapidez. Ocorrerá a formação de duas regiões onde haverá em cada uma a predominância de íons com sinais opostos, estabelecendo-se assim uma diferença de potencial $\Delta \mathrm{V}$. Além dos levantamentos em superfície, este fenômeno também é considerado em perfilagens de poços e em qualquer dos casos tem importância na determinação de porosidades (Orellana, 1972).

Esta diferença de potencial $\Delta \mathrm{V}$, devida ao surgimento das duas regiões de concentração de íons de sinais opostos, pode ser expressa como

$$
\Delta V=\frac{u-v}{u+v} \frac{R T}{n F} \ln \frac{C_{1}}{C_{2}}
$$

onde:

$\mathrm{u}, \mathrm{v}=$ mobilidades dos cátions e ânions, respectivamente.

$n=$ valência dos íons.

$R=8,314$ joules $/ \mathrm{mol} . \mathrm{K}$ (constante dos gases).

$T=$ temperatura absoluta (oK).

$F=96.487$ Coulombs/mol. (constante. de Faraday)

$C_{1}, C_{2}=$ concentrações dos eletrólitos em contato.

0 SP causado pelos potenciais de difusão aplica-se em questões ambientais e de engenharia. É fundamental nas perfilagens elétricas de poços onde estão em contato os eletrólitos contidos nas rochas com a lama da sondagem, servindo na determinação das porosidades das litologias. 


\section{Potenciais de Fluxo (streaming potential)}

Certamente é 0 de maior interesse em aplicações ambientais, geologia de engenharia e hidrogeologia. É devido ao movimento de fluidos através dos poros e descontinuidades das rochas e é também denominado de eletrofiltração ou eletrocinese. Este potencial pode ser a causa de anomalias de SP comumente correlacionadas com o relevo (topografia) e nas perfilagens SP, em que 0 fluido de perfuração penetra nas paredes do furo. As medidas deste tipo de potencial têm sido utilizadas na geologia de engenharia e na geologia ambiental, para detecção de caminhos preferenciais da água subterrânea, auxiliando o mapeamento de divisores d'água e direção de fluxo.

A magnitude do SP depende de algumas características do subsolo e do fluido percolante, como resistividade elétrica, constante dielétrica e viscosidade do fluido, continuidade do contato fluido/subsolo e diferenças de pressão ao longo do percurso do fluxo.

A passagem de um eletrólito através de uma membrana porosa produz uma diferença de potencial entre os dois lados da mesma. Considerando a porosidade do substrato como uma rede de capilares por onde percolam as águas de subsuperfície, então o comportamento do substrato pode ser visto como uma membrana. Os ânions são absorvidos pelas paredes dos capilares e irão atrair os cátions, estabelecendo-se desta maneira uma dupla camada elétrica. Os ânions permanecem fixos enquanto que os cátions são transportados através dos capilares pelo fluxo dos fluidos ali presentes, criando-se uma concentração destes últimos à saída. Surge então uma d.d.p., entre o ponto inicial e final do percurso, que obedece à equação de Helmholtz

$$
\Delta V=\frac{\zeta \varepsilon P}{\eta \sigma}
$$

onde:

$\zeta=$ diferença de potencial na dupla camada.

$\varepsilon=$ constante dielétrica.

$\sigma=$ condutividade

$\eta=$ viscosidade do eletrólito.

$\mathrm{P}=$ diferença de pressão hidrostática entre os extremos do capilar

- responsável pelo movimento do eletrólito.

0 potencial de fluxo mais importante é o "per descensum" (Schlumberger, 1929, apud Orellana, 1972): trata-se da infiltração d'água da chuva em terrenos permeáveis ou ao longo de faIhas/fraturas. Os cátions são removidos pela água e, nos locais topograficamente mais elevados, surgem núcleos eletricamente negativos. A Figura 1 ilustra o processo.
0 SP causado pelos potenciais de fluxo "per descensum" é utilizado nos estudos que visam a determinação dos fluxos subsuperficiais, como vazamentos em barragens e contaminações do lençol freático oriundas de aterros sanitários, lixões, produtos químicos etc.

\section{METODOLOGIA PARA O POTENCIAL ESPONTÂNEO (SP) Materiais e Equipamentos}

São utilizados eletrodos, cabos condutores e milivoltímetro. Os eletrodos devem ser do tipo não polarizável. Consistem de um metal mergulhado em uma solução saturada de um sal do próprio metal, como Cu em $\mathrm{CuSO}_{4}$ ou $\mathrm{Ag}$ em AgCl, contidos em um recipiente poroso (usualmente denominados "potes"). A porosidade é necessária para que se processe uma passagem lenta e suave da solução contida no pote para o solo, estabelecendo-se o contato. 0 dispositivo mais usual são eletrodos de cobre imersos em solução de sulfato de cobre.

0 milivoltímetro deve ter elevada impedância de entrada (preferencialmente maior que $10^{8} \Omega$ ), capaz de informar a polaridade da medida, rejeição a interferências AC, robustez para o trabalho de campo, precisão de pelo menos $1 \mathrm{mV}$ nas leituras, capacidade de realizar medidas no intervalo de -5 a $5 \mathrm{~V}$ e medir resistências de contato.

Os cabos de conexão entre os eletrodos de medidas e 0 instrumento devem ter um bom isolamento, não permitindo entradas de ruídos elétricos espúrios durante os levantamentos.

Um cuidado importante a ser adotado é o uso de apenas um par de eletrodos para o trabalho, no sentido de minimizar 0 erro cumulativo.

\section{Metodologia para Aquisição de Dados}

As técnicas comumente utilizadas são a técnica dos potenciais e a técnica dos gradientes. Teoricamente, as duas técnicas se equivalem, porém, na prática, são bastante distintas, sendo o primeiro método de uso mais recomendado.

Usualmente adota-se como convenção de polaridade do SP que o pólo negativo do milivoltímetro seja conectado ou referido à estação anterior ou à estação-base e o pólo positivo do instrumento seja referido ao eletrodo posicionado na estação que estiver sendo medida.

\section{Técnica dos Gradientes (ou eletrodos móveis)}

A técnica dos gradientes ou configuração de eletrodos móveis (Parasnis, 1971; Orellana, 1972; Telford et al., 1990) consiste em medir-se sucessivamente as diferenças de potencial entre dois 


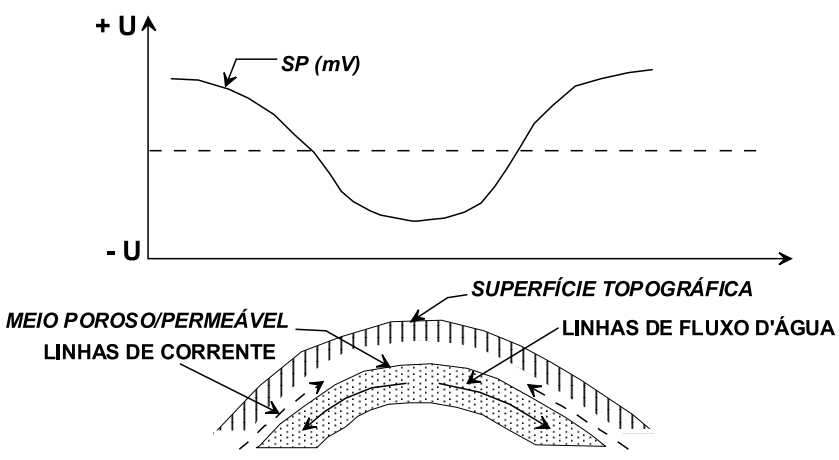

Figura 1 - Desenho esquemático do potencial de fluxo "per descensum".

pontos contíguos de um perfil. Após a tomada da medida entre os pontos, 0 arranjo é deslocado no perfil de medidas, normalmente a intervalos regulares e iguais. A Figura 2 ilustra 0 método dos gradientes.

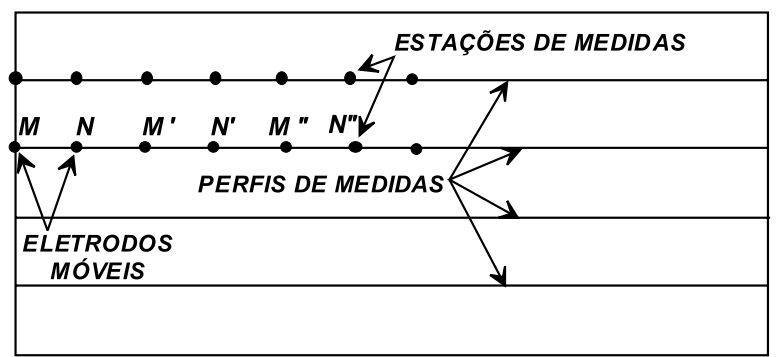

Figura 2 - Técnica dos Gradientes (Desenho original de Gallas, 2000).

0 SP de uma estação é obtido pela sucessiva adição das medidas entre os pontos de medição. Se o intervalo entre as medidas é pequeno em relação ao comprimento de onda da anomalia, a medida será 0 gradiente do potencial, $d V / d s$, do ponto médio entre as estações, sendo $d s$ a abertura entre eletrodos.

Uma vantagem desta configuração é o uso de fios curtos, de fácil e rápido deslocamento, além de minimizar efeitos indutivos que podem ocorrer com o emprego de cabos muito longos.

Entretanto, a maior desvantagem desta configuração é a alta susceptibilidade às anomalias espúrias geradas pelo erro cumulativo. As causas são, entre outras, efeitos do contato solo/eletrodos, polarização de eletrodos e derivas do potencial com 0 tempo. Os efeitos de polarização de eletrodos podem ser minimizados pelo procedimento de inversão dos eletrodos "leapfrog". Os outros erros, porém, são praticamente impossíveis de corrigir.

\section{Técnica dos Potenciais (ou base fixa)}

Como no caso da técnica dos gradientes, são empregados para a tomada de dados SP dois eletrodos de medidas. Nesta configuração requer-se que um dos eletrodos seja mantido fixo em uma estação-base, enquanto o outro percorre os pontos de medidas nos perfis ou malha de levantamento.

0 comprimento de ao menos um dos cabos de conexão terá de ter no mínimo a extensão do perfil a ser levantado e/ou alcançar todos os pontos da linha/malha objetivo do levantamento. A Figura 3 ilustra o procedimento em que a estação-base é o ponto do eletrodo $\mathrm{M}$ e as posições $\mathrm{N}, \mathrm{N}$ ' e N" referem-se às sucessivas posições do eletrodo itinerante.

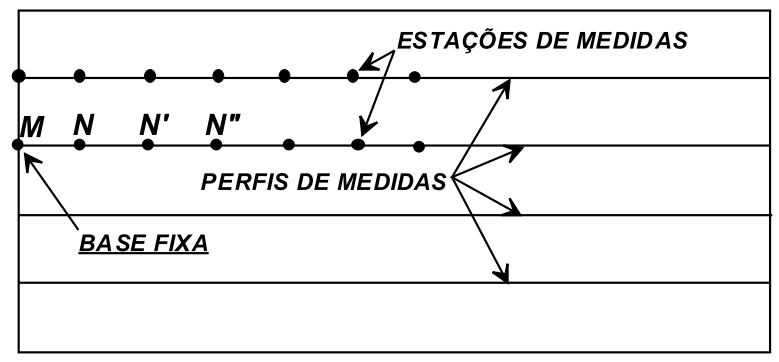

Figura 3 - Técnica dos Potenciais (Desenho original de Gallas, 2000).

0 levantamento é efetuado conectando um dos pólos do instrumento de medidas à base fixa e mantendo este junto à mesma. 0 outro pólo do instrumento é conectado ao eletrodo móvel que desloca-se ao longo dos perfis tomando as medições SP nas estações sucessivas. 0 deslocamento do eletrodo móvel é realizado por meio de um cabo, normalmente contido em uma bobina, que é desenrolada ou enrolada à medida que avança o levantamento.

Uma vez que o fio não é arrastado entre as estações, os danos causados ao mesmo são minimizados, favorecendo as condições de ser mantido um bom isolamento.

Em situações de perfis muito longos ou áreas muito grandes, por vezes torna-se necessária a transferência da base, fazendose a "amarração" da(s) nova(s) base(s) com a(s) anterior(es). Também pode ser necessária a mudança de base devido ao fato de 
que ao aumentarmos o tamanho do fio das medidas, este tornase uma espécie de antena que capta cada vez mais ruídos indesejáveis. Neste caso, a solução para encurtar-se o fio, pode ser a mudança de base.

A grande vantagem desta configuração, se comparada à técnica dos gradientes, é significativa diminuição no erro cumulativo. Enquanto que na técnica dos gradientes as medidas tinham no mínimo três possíveis erros cumulativos, aqui eles não se verificam (ou ao menos com muito menor importância).

A qualidade dos dados obtidos com esta técnica, geralmente é melhor do que a anterior e a possibilidade de mapear-se "anomalias" causadas por ruídos espúrios é menor.

Assim, a menos que existam dificuldades inerentes à área estudada para a coleta de dados com o dispositivo dos potenciais, é preferível esta configuração à configuração dos gradientes.

\section{Ruídos em Levantamentos SP - Correções e Cuidados}

Níveis de ruídos muito elevados podem mascarar a detecção de anomalias SP de interesse e constituem-se, em alguns casos, num grande problema. 0 ruído em levantamentos SP pode ser originado de fontes naturais ou artificiais, tais como correntes telúricas, atividades antrópicas, topografia etc. Também constituem-se em fontes de ruídos a polarização de eletrodos e derivas causadas por variações químicas do solo, temperatura e umidade.

As fontes de ruídos são as seguintes:

- Polarização de eletrodos e deriva;

- Diferentes condições de contato solo/eletrodos;

- Oscilações temporais;

- Ruídos diversos.

Para eliminar/minimizar os efeitos da polarização e deriva, admitindo que o erro devido a isso está contido entre a primeira e a última leitura realizada, a medida deste erro pode ser obtida medindo-se o SP entre os eletrodos com os mesmos imersos em uma solução do eletrólito ( $\mathrm{CuSO}_{4}, \mathrm{p}$. ex.) imediatamente antes da instalação do eletrodo-base e imediatamente após a retirada do mesmo.

Alternativamente, como no caso da magnetometria, quando não dispõe-se de um magnetômetro para estação-base, pode-se fazer 0 controle da deriva/polarização repetindo-se a leitura entre dois pontos a certos intervalos de tempo (a cada 2h, p. ex.).

Estes procedimentos permitirão a subtração da polarização e deriva, sendo as correções para medidas em tempos intermediários obtidas por interpolação.
Os efeitos de deriva e polarização de origem eletroquímica podem ser atenuados reduzindo-se o tempo de permanência (tempo de leitura) do eletrodo móvel em contato com o solo e limpandose o máximo possível os poros do eletrodo entre as estações de medida.

A deriva e os efeitos de polarização podem ser atenuados minimizando a exposição dos eletrodos a variações de temperatura e químicas. Isto é possível de ser feito mantendo-se o eletrodo da estação base em um local à sombra e, na medida do possível, também o eletrodo itinerante.

Quanto ao ruído introduzido aos dados de SP pelas diferentes condições de contato entre o solo e os eletrodos, estes são devidos principalmente às variações locais de umidade, condutividade, compactação do solo etc.

Estes erros em certos casos podem ser críticos, principalmente quando a técnica de levantamento empregada é a dos eletrodos móveis (gradientes).

Para minimizar estas variações, no caso de solos secos, devese fazer com que o eletrodo de medidas seja colocado em uma cova, de modo a evitar-se a parte superior do solo mais intensamente ressecada, evitando também as variações de temperatura.

Uma outra providência que pode ser tomada em casos de solos secos e/ou muito resistivos é a de proceder-se à escavação de todas as covas de medições previamente e umedecê-las com água. Tal procedimento, no entanto, deve ser feito com várias horas de antecedência, evitando-se variações de SP causadas pela infiltração da água no solo.

Situações extremas, como as que ocorrem em levantamentos sobre rochas expostas ou sobre áreas pavimentadas, podem ser minimizadas colocando-se o eletrodo - pote poroso - sobre uma esponja embebida na mesma solução $\left(\mathrm{CuSO}_{4}\right.$, p. ex.) contida no pote poroso.

Oscilações temporais do SP no decorrer de um levantamento são causadas por mudanças nas condições locais da área estudada, como as características do solo ou variações das resistividades do subsolo devidas a mudanças nos níveis de umidade. As causas principais destas oscilações são as mudanças nas propriedades do solo devidas a variações de temperatura, chuvas, presença de atividades de obras nas imediações, variações na profundidade do nível d'água etc.

Uma outra causa são os campos elétricos gerados por causas naturais (correntes telúricas) ou por fontes artificiais (causas antrópicas). São aquelas causadas por campos elétricos artificiais ou por correntes telúricas naturais geradas por oscilações no campo magnético terrestre.

Uma possibilidade de minimização deste e outros efeitos é 0 
tratamento dos dados com uma filtragem adequada, geralmente um filtro passa-baixa (ou passa-banda, discutido adiante), bem como 0 uso de registradores com amostragens do sinal medido em tempos apropriados.

Outros ruídos presentes em levantamentos SP são os causados pela topografia, aterramentos, objetos metálicos enterrados, sistemas de proteção à corrosão, depósitos minerais (se o objeto do trabalho não é a pesquisa mineral), potenciais eletroquímicos, potenciais de fluxo indesejados, variações na resistividade do subsolo, entre outros.

Objetos metálicos como revestimentos de furos de sondagens podem causar intensas anomalias SP negativas, em fenômeno de causas similares àquelas demonstradas por Sato \& Mooney (1960) para mineralizações que apresentem condutividade elétrica.

A topografia tende a refletir um caráter negativo nas medidas de SP à medida do incremento na topografia e é causado pelo movimento de descenso da água em relação à superfície do terreno.

Potenciais eletroquímicos indesejados podem acontecer nas superfícies de contato entre litologias de diferentes porosidades.

Mudanças nas vegetações também são passíveis de proporcionar ruídos indesejáveis em trabalhos de potencial espontâneo.

\section{Apresentação e Tratamento dos Dados de SP}

Os dados obtidos de levantamentos de potencial espontâneo podem ser apresentados sob a forma de mapas ou perfis. Quando sob a forma de perfis isolados, o único tratamento aplicado aos dados é, quando necessário, as correções devidas a alguns dos ruídos citados nos itens anteriores.

Se o levantamento abranger vários perfis e os resultados forem apresentados sob a forma de mapas, às vezes é necessário que os dados sejam submetidos a uma filtragem. Este procedimento visa eliminar os efeitos das diferenças de resistências de contato solo-eletrodos que por vezes situam os perfis em níveis de base distintos, reduzindo-os a um nível de base único. 0 processo também pode ser útil quando usam-se referenciais (bases) distintos.

Em levantamentos feitos em barragens de terra, nas proximidades das bermas (canalizações para águas pluviais ao longo da barragem), por exemplo, o grau de compactação ou mesmo o material constituinte do maciço é diferenciado. Sob estas condições, os perfis ao longo ou nas proximidades das bermas terão um nível de base de medidas diferente dos outros perfis. Isto resultará em um mapa em que as equipotenciais irão se circunscrever em torno dos perfis, mascarando os fluxos anômalos. Situações similares podem ocorrer em levantamentos onde parte da área é pavimentada com, por exemplo, cascalhos/pedras e parte em solo. Este tipo de situação é ilustrado nas Figuras 4 e 5, que mostram os blocos diagrama de SP em uma barragem de terra com bermas, antes e após a filtragem dos dados (passa-banda, no caso).

Na Figura 7 são mostrados dois perfis de levantamentos integrantes dos blocos diagrama (Figuras 4 e 5) que ilustram o processo de filtragem que reduz os dados a um mesmo nível de base.

0 processo de filtragem, na maioria das vezes, é feito através de um filtro digital do tipo passa-banda. Mais trabalhosa e sem a mesma precisão, a filtragem também pode ser feita manualmente. Por meio de uma análise visual pode-se eliminar os efeitos indesejáveis, como pode ser visto na Figura 6.

Além do efeito de redução de todos os perfis a um mesmo nível, a filtragem também pode realçar as feições do levantamento SP de interesse e diminuir os "ruídos" de altas freqüências indesejados. Isto é obtido pela escolha do tamanho da banda passante do filtro (frequiências de corte).

Os resultados de um levantamento SP podem ser interpretados qualitativamente ou quantitativamente. As interpretações quantitativas são geométricas, sendo calculadas as anomalias $\mathrm{SP}$ causadas por fontes de geometria simples. Estas fontes são polarizações na forma de pontos singulares, linhas, cilindros, esferas, lâminas, entre outras.

Na maioria das vezes, no entanto, a interpretação qualitativa é a que pode ser conseguida, devido a causas como ruídos, baixa ou insuficiente amostragem de dados etc. Felizmente, quase sempre esta interpretação é suficiente para alcançar as metas dos trabalhos.

\section{APLICAÇÕES DO SP - ALGUMAS CONSIDERAÇÕES E EXEMPLOS}

Originalmente o potencial espontâneo (SP) tinha sua aplicação na prospecção mineral, onde suas anomalias poderiam estar associadas à presença de corpos sulfetados e condutores.

Em casos de prospecção de água subterrânea em regiões cristalinas, os aqüíferos são invariavelmente associados à presença de fraturas armazenadoras de água que comportam-se como zonas de maior percolação/infiltração das águas subterrâneas, podendo ser identificadas através do SP (Gallas, 1999, 2000; Gallas \& Augusto Filho, 1999).

Em questões ambientais, o método pode ser de grande utilidade como indicativo de direções preferenciais de fluxos contaminados por poluentes, tais como chorume, hidrocarbonetos etc.

Especificamente em casos de barragens/represas de terra 


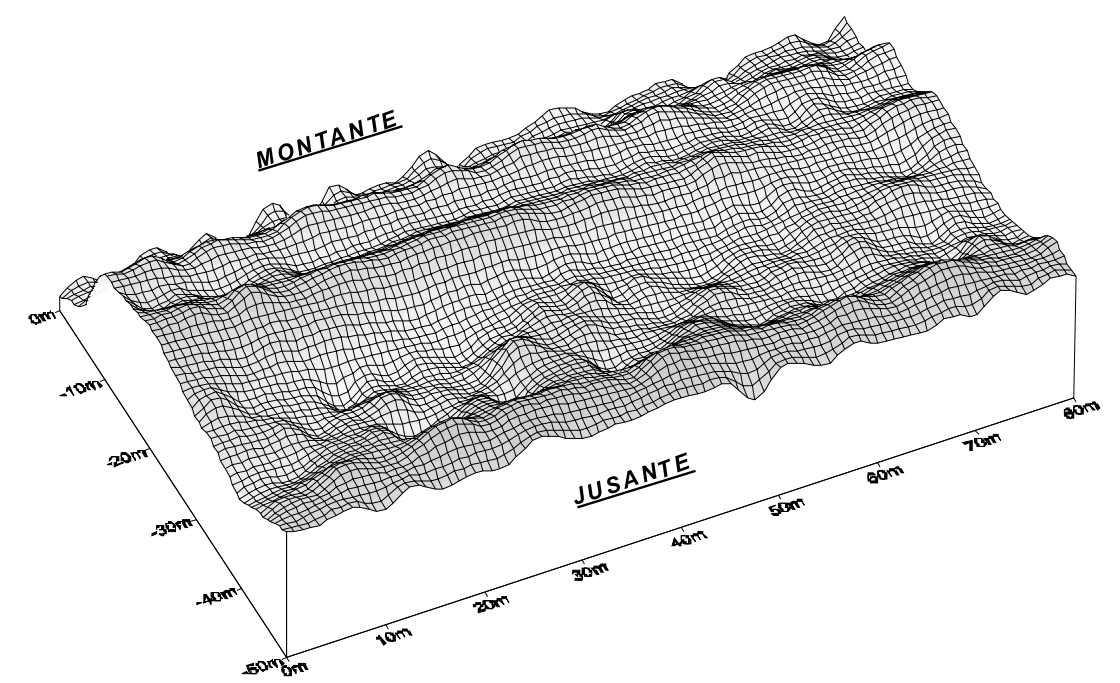

Figura 4 - Bloco diagrama de SP, dados em barragem de terra (dados brutos).

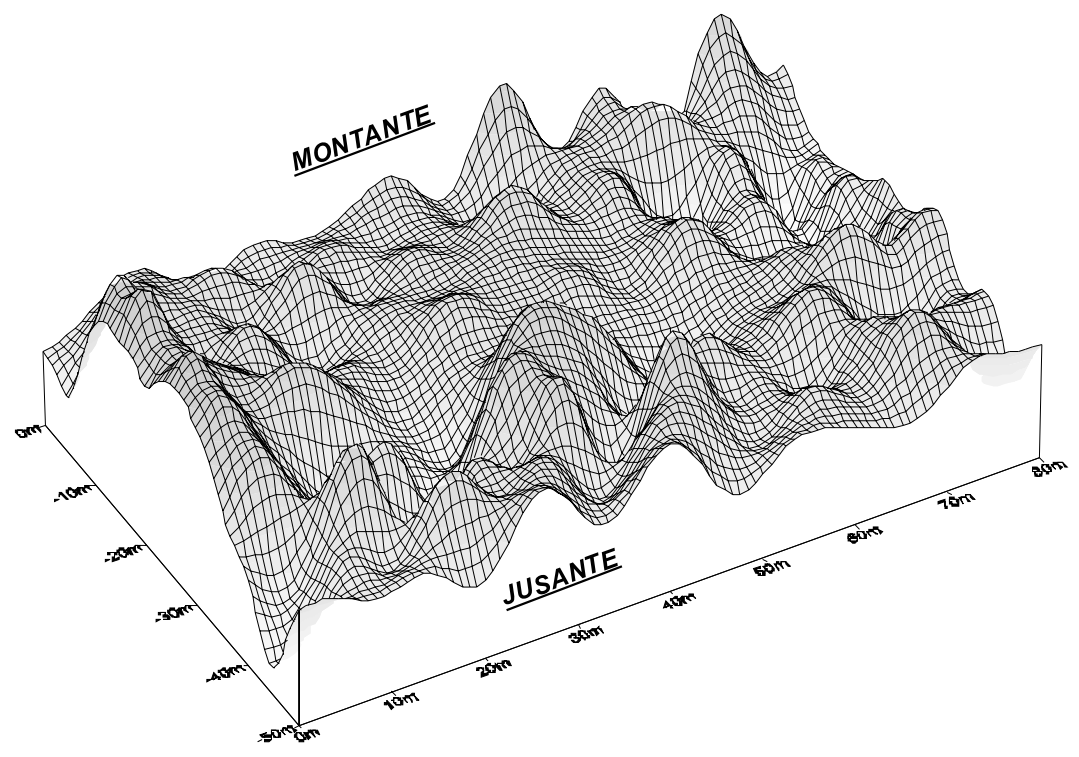

Figura 5 - Bloco diagrama de SP, dados em barragem de terra (dados filtrados).

e taludes ou encostas, não é difícil visualizar uma importante aplicação para o método SP, uma vez que concentrações de fluxos d'água em terrenos naturais ou artificiais podem causar sérios danos. Se os fluxos/infiltrações d'água atingirem concentrações ou velocidades críticas, ocorrerão processos erosivos ocasionando subsidências e eventual colapso de uma barragem, por exemplo.
Assim, um monitoramento sistemático preventivo ou levantamentos localizados em áreas suspeitas de fluxos anômalos no subsolo da barragem/talude podem ser muito valiosos.

A aplicação do método SP para investigações de fluxos em barragens de terra baseiam-se em medir-se os potenciais oriundos pelo movimento da água em um meio poroso (Bogoslovsky 


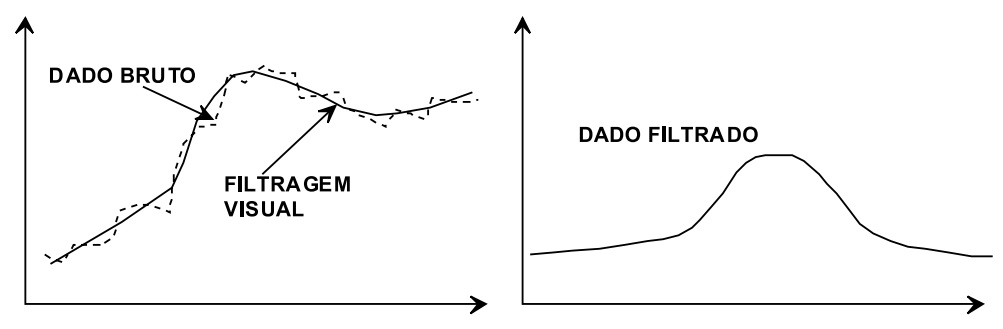

Figura 6 - Filtragem manual/visual.

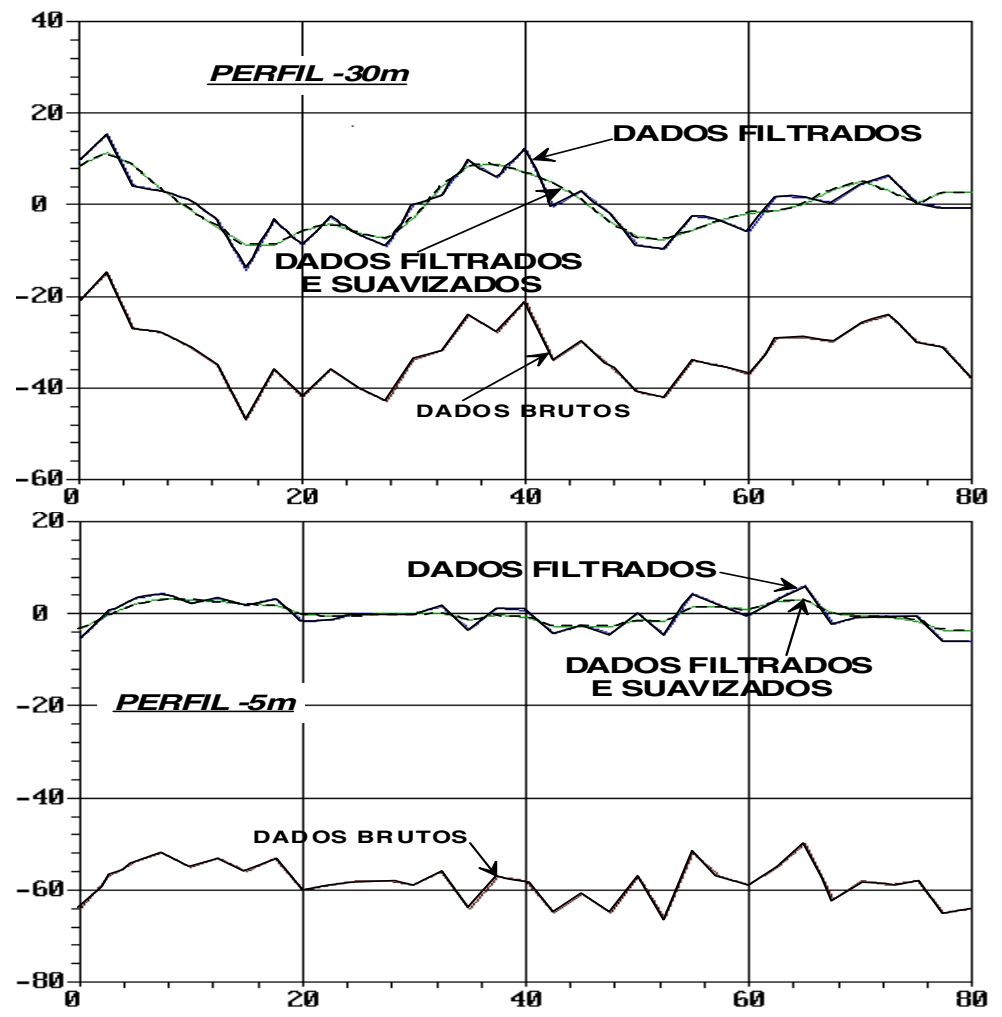

Figura 7 - Perfis de SP (perfis -30m e -5m da Fig. 4), dados brutos e filtrados.

\& Ogilvy, 1970a, 1970b, 1973a e 1973b). Trata-se fundamentalmente do estudo do processo de eletrofiltração (potenciais de fluxo).

Experimentos de laboratório (Ogilvy et al., 1969) demonstraram que existe uma relação entre a intensidade do potencial gerado, a porosidade do meio percolado, diferenças de pressão, concentrações de eletrólito (salinidade) e também a temperatura.

A intensidade dos potenciais gerados pode ser significativamente afetada se, por exemplo, houver a presença de materiais argilosos em um meio arenoso ou preenchendo um ambiente fraturado. Por outro lado, se a presença de minerais de argila acarreta uma diminuição da porosidade do meio, também proporciona o surgimento de um potencial devido ao fenômeno de adsorção, bastante intenso nos argilominerais.

Existe na natureza uma predominância de íons mono e bivalentes nas soluções salinas e a parte com mobilidade na dupla camada elétrica apresenta carga positiva. Se os íons positivos são transportados pelos fluxos d'água, então nos locais onde há a surgência destas águas é de esperar-se anomalias SP positivas.

Em regiões de permeabilidade uniforme, os potenciais de fluxo tendem a refletir os contornos do nível d'água. Os potenciais crescem na direção do fluxo e suas intensidades são proporcionais ao gradiente hidráulico. Ou seja, o sentido de deslocamento do fluxo é de um potencial elétrico menor para um maior. Um 
mapa de curvas equipotenciais de SP de uma área com iguais permeabilidades pode fornecer informações sobre a configuração, direção e intensidade dos fluxos, seja no plano horizontal como no vertical.

Tanto a direção como a polaridade dos sinais dos potenciais de fluxo podem ser distorcidas ou afetadas por fatores de natureza litológica. De um mapa de curvas equipotenciais de SP, além das indicações sobre o comportamento dos fluxos d'água, também é possível obter-se informações sobre heterogeneidades na distribuição dos materiais do subsolo que podem influenciar de alguma maneira as percolações em subsuperfície. Portanto, em locais onde exista uma elevada concentração de materiais argilosos, estes deverão ser indicados por anomalias positivas, enquanto que locais de acúmulo de materiais detríticos ou de maior porosidade, deverão apresentar anomalias negativas.

0 SP pode ser empregado em áreas de ocorrências de calcários, objetivando a detecção de anomalias associadas aos processos de carstificação. Trabalhos efetuados nestas áreas podem identificar anomalias SP nas imediações dos locais de ocorrências de carsts potencialmente sujeitas a colapsos de terreno.

0 SP também tem sido usado nos estudos geotermais e fontes associadas, uma vez que os fluxos de fluidos a temperaturas diferenciadas também são passíveis de detecção pelo método (Corwin et al., 1981; Apostolopoulos et al., 1997).

Schiavone \& Quarto (1984) empregaram o método em uma área costeira do sul da Itália onde fluxos ascendentes de água oriundos de um aqǘfero manifestam-se através de surgências de água. Os resultados obtidos associados às interpretações hidrogeológicas mostraram que os fluxos ascendentes estavam associados a descontinuidades no embasamento ou contatos litológicos. 0 levantamento também permitiu interpretar que as surgências d'água eram bem separadas e nem sempre associadas à localização de fontes.

Medeiros \& Lima (1999) usaram o SP, associado a eletrorresistividade, para locação de poços em rochas cristalinas fraturadas na região Nordeste, concluindo que a geração do SP, nestes casos, deve-se principalmente ao movimento das águas subterrâneas.

Um caso de utilização do método para investigação de áreas sujeitas a instabilidade de taludes é o publicado por Bogoslovsky \& Ogilvy (1977). Os autores empregaram o método em associação com levantamentos de eletrorresistividade, sísmica, magnetometria e medições de temperatura. Os trabalhos objetivaram a determinação de áreas de maior probabilidade de movimentos de solo em função dos parâmetros medidos.
0 US Army Engineer Waterways Experiment Station (WES) tem tido sucesso na aplicação do SP e outros métodos geofísicos para detectar, mapear e monitorar condições anômalas de infiltrações em reservatórios de água, aterros sanitários e depósitos de lixo de risco nos EUA (Corwin \& Butler, 1989). Mais recentemente, em parte devido ao sucesso do WES, aplicações na área de geotecnia do método SP, têm aumentado nos EUA, inclusive tendo sido desenvolvidos para este fim novos tipos de eletrodos impolarizáveis.

Embora seja possível a interpretação quantitativa do SP para que forneça taxas e profundidades dos fluxos, geralmente a qualidade e precisão dos mesmos não permitem esta quantificação, ficando como interpretação fundamental o mapeamento dos fluxos em planta.

\section{CONCLUSÕES}

Conforme exposto, existe mais de uma causa para as origens dos potenciais espontâneos ou naturais. Dependendo dos objetivos para o qual um determinado trabalho de SP seja realizado, a interpretação dos resultados levará em conta ou não certos aspectos.

Em prospecção mineral, normalmente as anomalias SP originadas por mineralizações sulfetadas condutivas são as mais intensas, sendo comuns anomalias de uma centena de milivolts ou mais. Outra característica destas anomalias é que são geralmente negativas. Além disso, trata-se de trabalhos realizados quase sempre em regiões ainda não sujeitas às atividades antrópicas, inexistindo ruídos desta natureza. Nestes casos, as maiores perturbações nas medidas que podem ocorrer, são aquelas causadas por oscilações nas resistividades dos terrenos e por efeitos topográficos. Geralmente na pesquisa mineral os ruídos presentes são menos críticos do que quando a aplicação do método é para outros fins. A ordem de grandeza das anomalias em prospecção mineral é quase sempre superior ao nível de ruído presente.

Por outro lado, quando a coleta de dados SP é dirigida a estudos hidrogeológicos, geologia de engenharia ou aplicações ambientais, as anomalias que ocorrem são, na maioria das vezes, de menor intensidade do que as devidas a mineralizações. Um outro dado a ser considerado nestes casos, é que a maioria dos locais estudados situam-se em áreas urbanas ou em suas imediações, sujeitas a um nível maior de ruídos do que as áreas de mineração.

Os dados geralmente podem ser apresentados sob a forma de perfis, mapas ou blocos diagrama 3-D. Dependendo da qualidade dos dados e objetivos do trabalho, serão efetuadas as correções 
devidas (ou até filtragens) dos dados.

Os resultados de um levantamento SP podem ser interpretados qualitativamente ou quantitativamente. As interpretações quantitativas são geométricas, sendo calculadas as anomalias SP causadas por fontes de geometria simples. Estas fontes são polarizações na forma de pontos singulares, linhas, cilindros, esferas, lâminas, entre outras.

Na maioria das vezes, no entanto, a interpretação qualitativa é a que pode ser conseguida, devido a causas como ruídos, baixa ou insuficiente amostragem de dados etc. Felizmente, quase sempre esta interpretação é suficiente para alcançar as metas dos trabalhos.

Em casos de SP relacionados a fluxos de águas em subsuperfície, as anomalias SP positivas geralmente ocorrerão em locais onde o fluxo das águas é ascendente em direção à superfície. Isto deve-se ao fato de que os íons positivos são transportados pelos fluxos d'água. Desta forma, nos locais onde há a surgência de águas é de esperar-se anomalias SP positivas.

Os potenciais crescem na direção do fluxo e suas intensidades são proporcionais ao gradiente hidráulico. Ou seja, o sentido de deslocamento do fluxo é de um potencial menor para um maior. Um mapa de curvas equipotenciais de SP de uma área pode fornecer informaç̃ões sobre a configuração, direção e intensidade dos fluxos.

É preciso ter em mente, no entanto, que tanto a direção como a polaridade dos sinais dos potenciais de fluxo podem ser distorcidos ou afetados por fatores de natureza litológica ou característica dos fluidos em movimento.

Assim, de um mapa de curvas equipotenciais de SP, também podem ser obtidas informações sobre as peculiaridades litológicas dos materiais do subsolo que podem interferir de algum modo no comportamento dos fluxos no subsolo. Portanto, em locais onde exista um maior conteúdo de argilominerais, estes deverão apresentar valores positivos, enquanto que locais de maior concentração de materiais detríticos ou de maior porosidade, as anomalias tenderão a ser negativas.

\section{REFERÊNCIAS}

APOSTOLOPOULOS G, IOANNIS L \& EVANGELOS L. 1997. The selfpotential method in the geotermal exploration of Greece. Geophysics, 62(6): 1715-1723.

BOGOSLOVSKY VA \& OGILVY AA. 1970a. Application of geophysical methods for studying the technical status of earth dams. Geophysical Prospecting, 18: 758-773.

BOGOSLOVSKY VA \& OGILVY AA. 1970b. Natural potential anomalies as a quantitative index of the rate of seepage from water reservoirs. Geophysical Prospecting, 18: 261-268.

BOGOSLOVSKY VA \& OGILVY AA. 1973a. Electrometric observations of antifiltrational cementation curtains. Geophysical Prospecting, 21: 296314.

BOGOSLOVSKY VA \& OGILVY AA. 1973b. Deformations of natural field near drainage structures. Geophysical Prospecting, 21: 716-723.

BOGOSLOVSKY VA \& OGILVY AA. 1977. Geophysical methods for the investigation of landslides. Geophysics, 42(3): 562-571.

CORWIN RF. 1990. The self-potential method for environmental and engineering applications. Geotechnical and Environmental Geophysics. Review and Tutorial. Society of Exploration Geophysicists, 1: 127-145.

CORWIN RF \& BUTLER DK. 1989. Geotechnical Applications of the SelfPotential Methods. Report 3. Development of self-potential interpretation techniques for seepage detection. Department of the Army. US Army Corps Engineers. Washington, DC, $71 \mathrm{p}$

CORWIN RF, DeMOULLY GT, HARDING JR. RS \& MORRISON HF. 1981. Interpretation of self-potential survey results from the East Mesa Geothermal Field, California. Journal of Geophysical Research, 86(B3): 18411848.

CORRY CE. 1985. Spontaneous polarization associated with porphyry sulfide mineralization. Geophysics, 50: 1020-1034.

GALLAS JDF. 1999. Geofísica - Uma Aplicação em Área Urbana de Ocorrência de Colapso de Terreno. Acta Geologica Leopoldensia, XXIII(49): 103-109.

GALLAS JDF \& AUGUSTO FILHO. 1999. Ensaios de eletrorresistividade, SP e IP em área de risco associado a colapso de terreno. In: Congresso Internacional da Sociedade Brasileira de Geofísica, VI, Rio de Janeiro. Anais... Rio de Janeiro, 1999, CD-R0M, Arquivo 264.RTF.

GALLAS JDF. 2000. Principais Métodos Geoelétricos e suas Aplicações em Prospecção Mineral, Hidrogeologia, Geologia de Engenharia e Geologia Ambiental. Rio Claro, 174p. Tese (Doutorado em Geociências e Meio Ambiente) - Instituto de Geociências e Ciências Exatas, Universidade Estadual Paulista.

GALLAS JDF \& MALAGUTTI FILHO W. 2001. 0 Método do Potencial Espontâneo (SP) na Detecção de Infiltrações em Barragens. In: Congresso Internacional da Sociedade Brasileira de Geofísica, VII; Salvador. Anais... Salvador, 2001, CD-ROM.

GAY SP. 1967. A 1800 millivolt self-potential anomaly near Hualgayoc, Peru. Geophysical Prospecting, 25: 236-245.

MEDEIROS WE \& LIMA OAL. 1999. Origem do potencial elétrico espontâneo em rochas cristalinas fraturadas e sua utilização na locação de poços. Revista Brasileira de Geofísica, 17(2,3): 103-116.

OGILVY AA, AYED MA \& BOGOSLOVSKY VA. 1969. Geophysical studies of water leakages from reservoirs. Geophysical Prospecting, 17: 36-62. 
OGILVY AA \& BOGOSLOVSKY VA. 1977. The possibilities of geophysical methods applied for investigating the impact of man on the geological medium. Geophysical Prospecting, 27: 775-789.

ORELLANA E. 1972. Prospeccion geoeletrica en corriente continua. Madrid: Paraninfo, $523 p$.

PARASNIS DS. 1971. Geofisica minera. Madrid: Ed. Paraninfo, 376p.
SATO M \& MOONEY HM. 1960. The electrochemical mechanism of sulfide self-potentials. Geophysics, 25: 226-249.

SCHIAVONE D \& QUARTO R. 1984. Self-potential prospecting in the study of water movements. Geoexploration, 22: 47-58.

TELFORD WM, GELDART LP \& SHERIFF RE. 1990. Applied geophysics. Second Edition. Cambridge: Cambridge University Press, 770 p.

\section{NOTAS SOBRE 0 AUTOR}

José Domingos Faraco Gallas. Bacharelou-se em Geologia pela Universidade Federal do Rio Grande do Sul em 1978. Concluiu mestrado em Geofísica em 1990 pela Universidade Federal do Pará. Doutorou-se em Geociências e Meio Ambiente, ênfase em Geofísica Aplicada pela UNESP - Universidade Estadual Paulista em 2000. Foi Pesquisador do Instituto de Pesquisas Tecnológicas do Estado de São Paulo - IPT de 1979 até início de 2002. Atualmente é Prof. Doutor do Instituto de Geociências da Universidade de São Paulo - USP e Prof. Adjunto II da Universidade do Vale do Rio dos Sinos - Unisinos. Áreas de interesse: geofísica aplicada à prospecção mineral, hidrogeologia, geologia de engenharia e geologia ambiental. 